\title{
О качестве обучения немецкому языку как второму (DaZ) в школах Германии
}

\author{
Безрукова Е.И., Колесников А.А. \\ Белгородский государственный национальный исследовательский университет \\ Россия, 308015, г. Белгород, ул. Победы, 85 \\ E-mail: besrukova@bsu.edu.ru; kolesnikov@bsu.edu.ru
}

\begin{abstract}
Аннотация. Современная система образования Германии переживает большие изменения. Одним из них является введение во всех типах немецких школ (от начальной до гимназии) нового учебного предмета «немецкий как второй язык». Это обусловлено миграционными процессами, происходящими в немецком обществе. Авторами рассматриваются педагогические и методические основы обучения немецкому как второму языку, а также проводится терминологическое отграничение понятия «немецкий как иностранный язык» и «немецкий как второй язык». Кроме того, авторы обращаются к характеристике таких терминов как «двуязычие» и «билингвизм». В центре внимания авторов актуальная ситуация в школах Германии в связи с обучением немецкому как второму языку. В результате педагогического наблюдения выделяются основные сложности преподавания немецкого как второго языка и обнаруживаются недостатки в системе и качестве обучения немецкому языку как второму. Анализируются причины возникающих сложностей и возможные пути их устранения. Авторы демонстрируют сложившуюся систему обучения на примере двух типов немецких школ - общеобразовательной школы и гимназии - для более объективного анализа. Впервые была подробно рассмотрена система обучения немецкому языку как второму в отличие от традиционной системы преподавания немецкого языка как иностранного.
\end{abstract}

Ключевые слова: система образования Германии, методика обучения немецкому языку, двуязычие, второй язык, немецкий язык как иностранный.

Благодарности: исследование проведено в рамках международного проекта по программе Европейского союза Erasmus+ No619477-EPP-1-2020-1-NL-EPPKA2-CBHE-JP «Улучшение внутренней оценки качества образования в сфере преподавания и обучения в вузах Азербайджана и России, IQAinAR».

Для цитирования: Безрукова Е.И., Колесников А.А. 2021. О качестве обучения немецкому языку как второму (DaZ) в школах Германии. Вопросы журналистики, педагогики, языкознания, 40 (2): 209-218. DOI: 10.52575/2712-7451-2021-40-2-209-218

\section{On the quality of teaching German as a second language (DaZ) in German Schools}

\author{
Elena I. Bezrukova, Alexei A. Kolesnikov \\ Belgorod National Research University, \\ 85 Pobeda St, Belgorod, 308015, Russia, \\ E-mail: besrukova@bsu.edu.ru; kolesnikov@ bsu.edu.ru
}

\begin{abstract}
Today's German education system is undergoing major changes. One of them is the introduction in all types of German schools (from primary school to gymnasium) of a new subject "German as a second language". The article deals with the pedagogical and methodological bases for teaching German as a second language and presents terminological distinction between "German as a foreign language" and "German as a second language". In addition, the authors consider different approaches to the definition of bilingualism. The authors focus on the current situation in German schools with regard to teaching German
\end{abstract}


as a second language. Through pedagogical observation main difficulties of teaching German as a second language are highlighted and drawbacks in the teaching system itself are revealed. The authors also analyse the reasons of described difficulties and the ways to cope with them. For more objective analysis, the current teaching system on the examples of two types of German schools, a comprehensive school and a gymnasium, is illustrated. The system of teaching German as a second language in contrast to traditional German as a foreign language was for the first time examined in detail.

Key words: German educational system, German language teaching methodology, bilingualism, second language, German as a foreign language.

Acknowledgements: The study was carried out within the framework of an international project under the European Union program Erasmus + No619477-EPP-1-2020-1-NL-EPPKA2-CBHE-JP "Improving the internal assessment of the quality of education in the field of teaching and learning in universities in Azerbaijan and Russia, IQAinAR".

For citation: Bezrukova E.I., Kolesnikov A.A. 2021. On the quality of teaching German as a second language (DaZ) in German Schools. Issues in Journalism, Education, Linguistics, 40 (2): 209-218 (in Russian). DOI: 10.52575/2712-7451-2021-40-2-209-218

\section{Введение}

Как известно, ФРГ является одной из ведущих Европейских стран, осуществляющих толерантную миграционную политику в отношении военных и политических беженцев. Такая политики привела к тому, что количество мигрантов в стране только лишь за 2015 год достигло 1 млн человек. В связи с этим было необходимо интегрировать новых жителей всех возрастов в немецкий социум. В настоящее время Германия продолжает принимать беженцев, а также поздних переселенцев, несмотря на сложность общей мировой ситуации в связи с пандемией коронавируса.

В этой ситуации появилась необходимость введения в немецких школах в учебные планы нового предмета «немецкий язык как второй» (Deutsch als Zweitsprache - общепринятое сокращение DaZ) в начале 2000-х годов. Но так как в Германии нет единой системы образования (каждая из 16 федеральных земель имеет свою систему школьного образования), соответственно нет и общего федерального распоряжения о введении DaZ. До этого времени $\mathrm{DaZ}$ преподавали в языковых школах и в языковых центрах преимущественно для иностранцев, которые приехали в Германию на работу. Предмет первоначально назывался "Gastarbeiterdeutsch" (немецкий язык гастарбайтеров) или "Deutsch für ausländische Arbeitnehmer". Введение DaZ было обусловлено политически, прежде всего политикой Ангелы Меркель по отношению к мигрантам. Поэтому количество учащихся школ, которым преподается DaZ, с каждым годом увеличивается. Следует заметить, что предмет DaZ обязателен и для детей мигрантов, которые родились в Германии, так как их родной язык (на котором говорят в семье) не немецкий.

В нашем исследовании мы предприняли попытку подробно рассмотреть и сравнить систему обучения немецкому как второму языку в школах Германии в связи с актуальностью самого объекта исследования для современного школьного образования в ФРГ.

Для достижения поставленной цели исследования были использованы следующие методы: теоретический анализ зарубежной литературы научно-методического направления, а также учебно-нормативных документов, сравнительный анализ, интерпретация зарубежной литературы; научно фиксируемое наблюдение, которое включает в себя сбор фактов, описание, обобщение и выделение закономерностей.

\section{Различия в системах обучения DaF и $\mathrm{DaZ}$}

Прежде чем рассматривать предмет DaZ, попытаемся терминологически отграничить его от смежного предмета DaF (Deutsch als Fremdsprache - немецкий язык как ино- 
странный). Учебный предмет $\mathrm{DaF}$ имеет достаточно глубокие корни в российской методике преподавания иностранных языков. Самым существенным отличием DaZ oт DaF является то, что DaF преподают (изучают) не в немецкоговорящих странах, и сам немецкий язык используется только лишь на занятиях. DaZ изучается в самой стране, где немецкий является государственным языком (Германия, Австрия, Швейцария) и на нем говорят большинство жителей ${ }^{1}$. Изучение $\mathrm{DaF}$ возможно и в Германии, если это непродолжительный (3-4 недели) интенсивный курс для иностранцев. Основное отличие заключается в том, что за рамками занятий нет никаких языковых контактов. Кроме того, изучение DaF носит системный характер, учебный материал четко структурирован, обучение строится часто на письменных текстах, много письменной тренировки, большое внимание отводится грамматическим правилам, обучению устной речи, говорение происходит путём симуляции реальных ситуаций (условная ситуация общения). Фокус обучения - это чтение и письмо. Можно сказать, что форма в этом случае превосходит содержание.

При изучении $\mathrm{DaZ}$ всё происходит наоборот, поскольку немецкий язык становится средством реального общения. Основным требованием является то, чтобы понять и быть понятым, то есть главным будет содержание. Тем самым изучение (обучение) носит ситуативный бессистемный характер, первичными будут аудирование (на улицах, в магазине, в транспорте и т.д.) и имитация. Часто правила выводятся интуитивно, из контекста, и даже с ошибками. Применение правил происходит в ситуации реального общения. Таким образом, содержание превалирует над формой. Говорящий ориентирован не на грамматическую правильность высказывания, а на коммуникативный успех. Фокус обучения - говорение и аудирование. Поэтому большое внимание на занятиях DaZ уделяется фонетике: необходим вводный фонетический курс, по возможности без письма ${ }^{2}$.

В российской системе обучения методика преподавания немецкого языка как иностранного достаточно хорошо разработана. Этому способствовало, становление методики обучения иностранным языкам как науки в 1920-1930 гг. и введение иностранного языка как обязательного предмета в общеобразовательных школах (чаще всего именно немецкого языка) и выделение его в отдельную группу языковых предметов. Базовые проблемы и категории методики широко исследованы в известных работах Л.В. Щербы, А.Н. Щукина, А.А. Миролюбова, Н.И. Гез, Н.Д. Гальсковой, И.В. Рохманова, Г.В. Роговой, Е.И. Пассова, И.Л. Бим и др. Методика преподавания немецкого языка как иностранного является частной методикой и представлена в работах Л.В. Фадеевой, А.Н. Шамова и др. Огромную методическую поддержку учителям, преподающим немецкий язык как иностранный (DaF) в России, оказывает Немецкий культурный центр им. Гёте (Goethe-Institut). B немецкоязычном пространстве теория и методика преподавания иностранного языка представлена работами Э. Апельтауэра, К.Б.Бёкманна, Й.Рохэ и мн.др.

\section{Второй язык и двуязычие}

Для дальнейшего рассмотрения объекта исследования необходимо обратиться к определению понятия «второй язык» (Zweitsprache) и «двуязычие» (Zweitsprachigkeit).

В немецкой научно-методической литературе нет общепринятой дефиниции термина «двуязычие» [Boeckmann, 1997]. Наиболее обобщённое определение этому понятию даёт У. Вейнрейх в своём научном исследовании. Двуязычие он рассматривает как попеременное использование двух языков [Weinreich, 1977]. С точки зрения степени освоения обоих языков такое обобщенное определение вызывает множество вопросов. Дж. Маклафин пытается найти компромисс среди различных определений, часто достаточно крайних

${ }^{1}$ Kuhnecke A. DaF oder DaZ - Was ist der Unterschied? URL: https://www.telc.net/ verlagsprogramm /ueber-telc/daf-wissensportal/lernen-lernen/unterschied-daf-daz.html (accessed: 15.03.2021)

${ }^{2}$ Böschel C. Didaktikblog für DaF und DaZ. URL: https://www.daf-daz-didaktik.de (accessed: 15.03.2021) 
по отношении друг к другу: с одной стороны, предъявляются довольно высокие требования к коммуникативной компетенции, т.е. к уровню овладения обоими языками, вплоть до уровня компетентного пользователя (как родным языком) [Кӧрре, 1997]. С другой стороны, каждого человека можно рассматривать двуязычным в том случае, если он овладел вторым языком в той мере, чтобы это позволило ему общаться.

Кроме того, следует делать отличие между «естественным, натуральным» двуязычием и «искусственным, приобретенным». В первом случаем термин «двуязычие» аналогичен понятию «билингвизм». Билингвы - это люди, которые осваивают два языка одновременно в обычных, естественных условиях, в ситуациях повседневного реального общения. В противоположность этому «культурное» двуязычие характеризуется тем, что освоение второго языка происходит в определенном учреждении (например, в школе), а сам язык не является средством повседневного общения, т.е. условна ситуация общения для второго языка [Boeckmann, 1997]. «Естественное» двуязычие мы наблюдаем в том случае, если каждый из родителей говорит с ребёнком на своём родном языке, с «искусственным» двуязычием мы имеем дело, «если в одноязычной семье родители подражают естественному двуязычию.... Чаще всего родители не справляются, и в один прекрасный момент сдаются» (пер. автора) [Kielhöfer, 1998, s. 14]. Такому скептическому определению Й. Штефаник противопоставляет термин «интернациональный билингвизм», который заменяет понятие «искусственное» двуязычие [Štefánik, 2005].

Далее различают «элитарное» и «просторечное» двуязычие. В первом случае речь идёт о привилегированной возможности изучать второй язык, во втором случае о принуждении к изучению, поскольку большинство людей в окружении говорят на этом языке [Boeckmann, 1997].

Кроме того, различают раннее и позднее двуязычие. При таком различии нужно также дифференцировать понятия «овладение языком» и «изучение языка». Раннее двуязычие имеет место в том случае, если второй язык усваивается до окончания первого этапа языкового развития ребенка (приблизительно до 10 лет), когда язык изучается имитативно, по аналогии. После этого начинается осознанное изучение второго языка, которое напоминает изучение иностранного языка, на основе его (грамматической) системы. Здесь идет речь о первичном и вторичном билингвизме: первичный билингвизм рассматривается как одновременное овладение двумя языками, а вторичный - как овладение вторым языком после первого [Apeltauer, 1997].

\section{Система обучения DaZ в немецкой школе}

Таким образом, предмет $\mathrm{DaZ}$ как раз и представляет собой систему овладения вторым языком в школьных условиях. Предмет DaZ реализует две основные цели:

1. Овладение немецким языком и дальнейшее развитие коммуникативной компетенции минимум до уровня A2 (в соответствии с GER - Gemeinsamen Europäischen Referenzrahmen - система определения уровня владения языком $)^{1}$, в лучшем случае до В1 в устной и письменной речи.

2. Подготовка учащихся к переводу в школьный класс для дальнейшего освоения всех учебных предметов на немецком языке, т.е. к выполнению задания любого типа по предметам школьной программы.

Принято считать, что эти цели достигаются без ограничений и условий в среднем спустя 5 лет с момента изучения DaZ. Для того, чтобы успешно осваивать школьные предметы, DaZ-ученики (ученики, изучающие немецкий язык как второй) должны овладеть и «школьным» языком (Bildungssprache/Schulsprache). Это требование относится прежде всего к письменному языку, основными качествами которого являются абстракт-

${ }^{1}$ Gesamteuropäischer Referenzrahmen. URL: http://www.europaeischer-referenzrahmen.de (accessed: 07.03.2021) 
ный характер, четкая структура, сложное языковое оформление. Кроме того, он предметно ориентирован и монологичен. Поэтому «школьный язык» часто формируется намного позднее, чем DaZ, на устном разговорном уровне. Овладение школьным языком предполагает использование определенной терминологии (в соответствии с предметом), умение работать с разными типами текстов и пользоваться различными операторами, например, записать протокол, описать диаграмму, интерпретировать литературный источник и т.д. ${ }^{1}$

При обучении DaZ (точнее перед началом определенного курса) необходимо диагностировать уровень языкового развития учащихся. Это происходит, как правило, при поступлении в школу. Дети мигрантов, которые родились в Германии, при поступлении в начальную школу проходят языковое тестирование в дошкольных учреждениях за год до начала обучения.

$\mathrm{B}$ процессе обучения DaZ необходимо постоянно наблюдать за языковым развитием учащихся. Это происходит не на интуитивном уровне, а с помощью систематического документирования. Для этого используют различные методы диагностики уровня языкового развития. Наиболее известными являются профильный анализ по В. Грисхаберу, Стест (это письменный экзамен, на основе которого проверяется уровень знания немецкого языка каждого учащегося) и описание уровней DaZ [Heilmann, 2013]. Многие немецкие школы отходят от общепринятых методик и разрабатывают свои анкеты наблюдений. Министерства образования многих федеральных земель предлагают свои разработки по анкетированию ${ }^{2}$. Использование такого рода анкет предполагает индивидуальный подход и учет результатов наблюдения коллектива учителей.

Сложность для преподавателей DaZ представляют также и сами группы DaZучеников, поскольку они выражено гетерогенные. Гетерогенность касается не только уровня успеваемости и способностей учащихся, как это встречается в традиционном классе, но и возраста, страны происхождения, языка, уровня образования, мотивации, биографии, условий проживания в семье, психического состояния и эмоциональной нагрузки. Это встречается и на второй ступени школьного образования, куда поступают дети (молодые люди), которые ранее никогда не обучались иностранному языку. Задача учителя в таком случае заключается в том, чтобы создать такие условия, в которых все учащиеся смогут развиваться. Из опыта DaZ-учителей известно, что вновь прибывшие дети ведут себя очень сдержанно, никак себя не проявляют, пассивны. В соответствии с такой ситуацией на DaZ-учителя возлагается функция быть первым контактным лицом в школе, к которому ребёнок может всегда обратиться. Со стороны учащихся встречается часто непонимание, вплоть до отторжения самой системы обучения в школе, поскольку их прежний опыт был другим. Во многих странах школьная система построена на преимущественно фронтальном методе обучения и на постоянном заучивании учебного материала, в то время как в школах Германии стремятся к развитию самостоятельного, автономного учащегося - автодидакта. Кроме того, очень важно для DaZ-учителя как можно ранее обнаружить у ребенка имеющийся потенциал и таланты. Таким образом ребенок сможет проявить себя независимо от языкового дефицита (например, в спорте или музыке) и тем самым, благодаря позитивным эмоциям и возможно новым социальным контактам, быстрее адаптироваться к изменившейся среде, что в свою очередь будет способствовать более прогрессивному языковому развитию.

Oсобое значение имеет соотношение DaZ-учеников в DaZ-группе. Учитель должен внимательно следить за тем, чтобы не образовывались группировки, а также не было аут-

${ }^{1}$ Baumann I., Neuhof I. 2017. DaZ-Unterricht in der Schule. Infos und Tipps für den schnellen Einstieg in die Praxis. URL: https://static.klett.de/klett/livebooks/W830234/ (accessed: 10.03.2021)

${ }^{2}$ Bildungsportal Niedersachsen. Formblätter und Materialien. 2016-2020. URL: http://www. landesschulbehoerde-niedersachsen.de/bu/schulen/schulentwicklung/sprachbildungszentren /formblaetter -materialien (accessed: 01.02.2021) 
сайдеров. Это происходит тогда, когда учащиеся, говорящие на одном и том же родном языке, садятся рядом и общаются не на немецком языке (во время выполнения заданий и в перерывах). Это может влиять на обучение положительно (взаимопомощь при выполнении заданий), но учителю лучше заранее обговорить с учениками возможность использования родного языка на его уроках.

Предмет DaZ является достаточно «молодым» по отношению к другим школьным предметам. Первый учебный план по немецкому как второму языку был разработан Министерством образования и культуры Баварии в 2001 году. И только к настоящему времени все 16 федеральных земель Германии имеют соответствующие учебные планы, опубликованные на их образовательных порталах. Например, учебный план по DaZ в Тюрингии был разработан Министерством образования, молодежи и спорта Тюрингии в 2020 году и в настоящий момент проходит апробацию [Deutsch als ..,, 2020]. В нем отражена концепция обучения DaZ Министерства образования Тюрингии. Данный учебный план традиционно включает в себя описание целей, результатов (компетенций), содержания обучения, оценку результатов и предполагает обучение DaZ в три этапа: вводный, основной и продвинутый курсы.

\section{Анализ системы обучения на примере школ г. Эрфурт (Тюрингия)}

Для анализа и сравнения системы обучения DaZ мы выбрали две школы в г. Эрфурте (Земля Тюрингия): общеобразовательная школа № 3 (Regelschule Nr. 3 „KolpingSchule“") и гимназия № 10 (Staatliches Gymnasium Nr. 10). Необходимо отметить, что средний этап школьного образования в Германии представлен несколькими типами школ, в каждой федеральной земле не менее 3 различных типов. Например, в Тюрингии их 4: общеобразовательная школа (Regelschule), гимназия (Gymnasium), общая школа (Gemeinschaftsschule) и интегрированная школа (Gesamtschule). Имеет место и специальная школа (Förderschule), в которой учатся дети с особыми потребностями с психическими и физическими задержками в развитии). Разница между названными школами средней ступени довольно существенна, она касается содержания обучения, набора учебных предметов, системы обучении в целом, но главное - уровня образования ученика, закончившего курс обучения. Учащиеся, окончившие гимназию и успешно сдавшие выпускные экзамены после 12 класса, получают аттестат зрелости, дающий право на поступление в любой университет (или вуз) в Германии. Ученики общеобразовательной школы также сдают экзамены, но после выпускного 10 класса, и получают аттестат об окончании общеобразовательной школы, который позволяет получить в дальнейшем среднее профессиональное образование [Thüringer Ministerium ..., 2018, с. 2].

Таким образом, требования к успеваемости учащихся гимназии изначально выше, чем в общеобразовательной школе. Это требование касается и уровня владения немецким языком. Очевидно, что количество DaZ-учеников в общеобразовательной школе будет выше, чем в гимназии, поскольку большинство мигрантов (беженцев) прибывают без специальной языковой подготовки. Исключение составляют в основном дети «трудовых» мигрантов, которых приглашают в Германию работодатели как высококвалифицированных специалистов. Их дети как раз и попадают в гимназию, т.к. часто владеют языком в достаточной мере. Так в 2019-2020 учебном году в общеобразовательной школе № 3 обучалось 18 DaZ-учеников, а в гимназии № 10 - 7. В соответствии с этим количество учителей, преподающих немецкий как второй язык в общеобразовательной школе № 3 в 2,5 раза больше. В гимназии достаточно иметь в штате одного учителя, работающего с полной нагрузкой, а в общеобразовательной школе в 2019-2020 учебном году 2 учителя преподавали исключительно DaZ, 1 учитель - только определённое количество часов (аналогично 0,5 ставки в России).

Отметим и тот факт, что наличие в школе учителя DaZ явление непостоянное. Каждый год ситуация в каждой конкретной школе меняется в зависимости от количества 
сайдеров. Это происходит тогда, когда учащиеся, говорящие на одном и том же родном языке, садятся рядом и общаются не на немецком языке (во время выполнения заданий и в перерывах). Это может влиять на обучение положительно (взаимопомощь при выполнении заданий), но учителю лучше заранее обговорить с учениками возможность использования родного языка на его уроках.

Предмет DaZ является достаточно «молодым» по отношению к другим школьным предметам. Первый учебный план по немецкому как второму языку был разработан Министерством образования и культуры Баварии в 2001 году. И только к настоящему времени все 16 федеральных земель Германии имеют соответствующие учебные планы, опубликованные на их образовательных порталах. Например, учебный план по DaZ в Тюрингии был разработан Министерством образования, молодежи и спорта Тюрингии в 2020 году и в настоящий момент проходит апробацию [Deutsch als ..,, 2020]. В нем отражена концепция обучения DaZ Министерства образования Тюрингии. Данный учебный план традиционно включает в себя описание целей, результатов (компетенций), содержания обучения, оценку результатов и предполагает обучение DaZ в три этапа: вводный, основной и продвинутый курсы.

\section{Анализ системы обучения на примере школ г. Эрфурт (Тюрингия)}

Для анализа и сравнения системы обучения DaZ мы выбрали две школы в г. Эрфурте (Земля Тюрингия): общеобразовательная школа № 3 (Regelschule Nr. 3 „KolpingSchule“") и гимназия № 10 (Staatliches Gymnasium Nr. 10). Необходимо отметить, что средний этап школьного образования в Германии представлен несколькими типами школ, в каждой федеральной земле не менее 3 различных типов. Например, в Тюрингии их 4: общеобразовательная школа (Regelschule), гимназия (Gymnasium), общая школа (Gemeinschaftsschule) и интегрированная школа (Gesamtschule). Имеет место и специальная школа (Förderschule), в которой учатся дети с особыми потребностями с психическими и физическими задержками в развитии). Разница между названными школами средней ступени довольно существенна, она касается содержания обучения, набора учебных предметов, системы обучении в целом, но главное - уровня образования ученика, закончившего курс обучения. Учащиеся, окончившие гимназию и успешно сдавшие выпускные экзамены после 12 класса, получают аттестат зрелости, дающий право на поступление в любой университет (или вуз) в Германии. Ученики общеобразовательной школы также сдают экзамены, но после выпускного 10 класса, и получают аттестат об окончании общеобразовательной школы, который позволяет получить в дальнейшем среднее профессиональное образование [Thüringer Ministerium ..., 2018, с. 2].

Таким образом, требования к успеваемости учащихся гимназии изначально выше, чем в общеобразовательной школе. Это требование касается и уровня владения немецким языком. Очевидно, что количество DaZ-учеников в общеобразовательной школе будет выше, чем в гимназии, поскольку большинство мигрантов (беженцев) прибывают без специальной языковой подготовки. Исключение составляют в основном дети «трудовых» мигрантов, которых приглашают в Германию работодатели как высококвалифицированных специалистов. Их дети как раз и попадают в гимназию, т.к. часто владеют языком в достаточной мере. Так в 2019-2020 учебном году в общеобразовательной школе № 3 обучалось 18 DaZ-учеников, а в гимназии № 10 - 7. В соответствии с этим количество учителей, преподающих немецкий как второй язык в общеобразовательной школе № 3 в 2,5 раза больше. В гимназии достаточно иметь в штате одного учителя, работающего с полной нагрузкой, а в общеобразовательной школе в 2019-2020 учебном году 2 учителя преподавали исключительно DaZ, 1 учитель - только определённое количество часов (аналогично 0,5 ставки в России).

Отметим и тот факт, что наличие в школе учителя DaZ явление непостоянное. Каждый год ситуация в каждой конкретной школе меняется в зависимости от количества 
учащихся и их скорости освоения предмета. Так, в 2020-2021 учебном году в гимназии № 10 уже нет постоянного учителя $\mathrm{DaZ}$, есть только учитель, закрепленный за школой, который одновременно преподаёт $\mathrm{DaZ}$ в нескольких гимназиях г. Эрфурта. Причиной является сокращение часов DaZ, т.к. почти все DaZ-ученики достигли уровня B1-B2 и не нуждаются в интенсивном изучении предмета. Новых учеников в 2020-2021 учебном году в гимназию № 10 не поступало.

В общеобразовательной школе № 3 можно наблюдать другое явление - количество учеников там стабильно увеличивается, и, соответственно, количество учителей не снижается. Но общим для обоих учебных учреждений остается тот факт, что Управление образования Центральной Тюрингии (Staatliches Schulamt Mittelthüringen) принимает учителей $\mathrm{DaZ}$ лишь на условиях временного договора, в то время как учителя, преподающие другие предметы, работают по бессрочным контрактам. В таком случае мы наблюдаем своего рода неблагоприятные рабочие условия для DaZ-учителей, поэтому многие учителя, имеющие право преподавать 2-3 предмета (включая немецкий как второй язык), редко специализируются на DaZ. Это привело в последние годы к острой нехватке профессиональных педагогических кадров по этому предмету. Как следствие, в школы на работу в качестве учителя $\mathrm{DaZ}$ принимают преподавателей, имеющих иностранный диплом учителя немецкого языка как иностранного $(\mathrm{DaF})$ даже без опыта преподавания в школе (например, мигрантов из России, Украины, Грузии).

Перейдём к анализу и сравнению групп DaZ-учеников в названных школах. При поступлении в общеобразовательную школу или в гимназию для учащихся нет требования по владению немецким языком. Таким образом, практически 100 \% поступивших учеников из других стран начинают параллельно с обучением в обычном классе изучение немецкого языка в отдельной группе, т.е. посещение предмета DaZ. Так, в гимназии № 10 в 2019-2020 учебном году было 2 группы DaZ-учеников: в первой группе проходили интенсивное обучение с начального уровня 4 ученика, поступившие в гимназию в 2019 году (12 часов в неделю), а во второй - 3 ученика с языковым уровнем В1, поступившие в гимназию ранее (2 часа в неделю). Но и такое разделение на группы было достаточно условным, поскольку в первой группе из 4 человек 1 ученица поступила в гимназию, обладая коммуникативной компетенцией на уровне A1-A2, а во второй группе из 3 учеников двое свободно владели устной речью, но нуждались дополнительно в формировании учения письменной речи. Как мы видим, даже при таком распределении по DaZ-группам с минимальным количеством учащихся невозможно избежать их гетерогенности.

Подобную картину мы наблюдали и в общеобразовательной школе № 3: 16 учащихся были распределены на 3 группы, а двое обучающихся находились на индивидуальном обучении (по 1 часу в неделю). Распределение групп было следующее: наиболее многочисленная группа уровня А1 и А2 состояла из 10 человек. Две остальные группы состояли каждая из 3 человек. Обе немногочисленные группы включали в себя только что поступивших DaZ-учеников: в одной группе обучались с начального уровня дети, ранее посещающие школу в другой стране, а другая группа была представлена детьми, которые никогда не обучались в школе. В этом и заключается одно из основных отличий преподавания DaZ в общеобразовательной школе: именно на базе общеобразовательных школ организовываются «курсы грамотности» (Alphabetisierungskurs). В связи с этим на учителя $\mathrm{DaZ}$ возлагается не только обязанность преподавания немецкого языка как второго, но и культурное просвещение таких учеников, не имеющих никакого школьного опыта, хотя их возраст от 10 до 16 лет. Так, например, учитель $\mathrm{DaZ}$ должен научить правильно держать ручку при письме, показать и объяснить, для чего нужны школьные принадлежности, а также приобщить этих учеников к школьной жизни. DaZ ученики, которые проходят «курс грамотности», посещают только немецкий как второй язык до того момента, пока они не будут готовы обучаться в регулярном классе. При распределении в класс они продолжают обучение $\mathrm{DaZ}$ по индивидуальному плану. 
Что касается индивидуального плана, то он составляется руководством школы совместно с учителем $\mathrm{DaZ}$ для каждого DaZ-ученика с учетом его языкового развития. На основе этого и выделяются DaZ-группы. Система обучения DaZ по индивидуальным планам введена во всех школах Тюрингии.

Спецификой предмета DaZ как в гимназии, так и в общеобразовательной школе является то, что этот предмет не оценивается, т.е. при выставлении оценок по учебным предметам за полугодие и за учебный год этот предмет даже не включен в перечень. Тесты проводятся исключительно для определения уровня владения коммуникативной компетенцией.

Примечателен и тот факт, что для DaZ-учеников, обучающихся в гимназиях г. Эрфурта (в том числе в гимназии № 10) в сентябре 2020 года был организован дополнительный интенсивный курс DaZ, который могли посещать те ученики, которые ещё не достигли на этот момент языкового уровня A2-B1. Эта дополнительная мера свидетельствует об озабоченности руководителей образовательных организаций уровнем преподавания $\mathrm{DaZ}$ в отдельных гимназиях и их стремлении улучшить ситуацию в целом.

Отметим также и тот момент, что в школах и в гимназиях (это касается гимназии № 10 и общеобразовательной школы №3) нет УМК по DaZ, рекомендованных Министерством Тюрингии в сфере образовании, молодежи и спорта, как, например, УМК по математике или немецкому языку как родному языку. В школе № 3 использовали в качестве основного учебного пособия "Prima plus - Leben in Deutschland - DaZ für Jugendliche: Schülerbuch" (2016) известного издательства Cornelsen, уровень A1 и А2; в гимназии обучались по учебному пособию "Das DaZ-Buch" не менее известного издательства Klett, уровни A1-B1. Оба учебных пособия предназначены для учащихся школ и гимназий средней ступени обучения, для которых немецкий язык не является родным. Важным отличием этих учебных пособий является и тот факт, что они нацелены не только на обучение немецкому как второму языку, но и формируют «школьный язык», а также необходимые языковые навыки и умения для овладения другими школьными предметами в рамках программы.

\section{Заключение}

Подводя итоги, необходимо отметить, что система обучения DaZ в школах Германии носит ситуативный, спонтанный характер, варьируется в зависимости от ситуации в каждой школе. Можно констатировать тот факт, что система ещё не сложилась, не выработана в том виде, как принято понимать в методике обучения иностранным языкам. Например, в сравнении с системой обучения немецкому языку как иностранному DaF (Deutsch als Fremdsprache) в России, где присутствуют все необходимые методические составляющие: стандартизированный институт квалифицированных кадров - учителей немецкого языка, система стандартов и учебных программ, УМК, рекомендованные Министерством просвещения РФ и т.д. С одной стороны, спонтанный, «бессистемный» характер обучения DaZ обусловлен спецификой самого предмета, который как раз и изучается в зависимости от ситуации, от необходимости использования немецкого языка. С другой стороны, это можно объяснить новизной и недостаточной определённостью предмета $\mathrm{DaZ}$, т.е. система только вырабатывается, находится на начальной стадии развитии.

Из вышесказанного следует, что вопрос о качестве обучения немецкому языку как второму можно поставить под сомнение. Как известно качество обучения складывается из качества образовательной среды и качества результатов. Образовательная среда (при обучении $\mathrm{DaZ}$ ) ещё не приобрела системный характер в том виде, чтобы можно было применять её повсеместно. Качество результатов оценить ещё сложнее, поскольку нет строгой системы критериев. Результаты, как было сказано ранее, индивидуальны и специфичны и практически никак не фиксируются.

Кроме того, снижению качества обучения DaZ будет способствовать общая ситуация со школьным образованием в Германии в связи с пандемией коронавируса. Как из- 
вестно, домашнее обучение было введено в Германии в марте 2020 г.: 100 \% обучения проходило в домашних условиях с марта по май 2020 г., в июне - июле 2020 г. домашнее обучение составляло 50 \% (т.е. частично дети посещали школу). С сентября 2020 г. учащиеся вернулись в школы почти со 100 \% учебной нагрузкой, но при этом некоторые предметы убрали из школьных планов. С декабря 2020 г. по февраль 2021 г. снова был введен карантин и, соответственно, домашнее обучение. С марта 2021 г. школы работали с $50 \%$ учебной нагрузкой. В таких условиях преподавание DaZ стало затруднительным. Вопервых, большинство школ ввели новые рабочие планы (например, исключили такие предметы, как «этика» и «спорт») и новое расписание уроков с ограничениями (например, не более 5 уроков в день). Во-вторых, DaZ-ученики оказались в разных группах, на которые разделили классы, соответственно они посещают школу в разные дни недели. Все эти обстоятельства усложняют преподавание $\mathrm{DaZ}$, который как бы «надстраивается» надо всей школьной системой, носит своего рода дополнительный, факультативный характер. Сложности и, соответственно, снижение качества обучения представляет собой само домашнее обучение, когда преподавание $\mathrm{DaZ}$ сводится лишь к выполнению письменных заданий: тренируется грамматика, орфография, формируется умение чтения, частично аудирования, но полностью отсутствует говорение. Таким образом, DaZ-ученики ограничены домашней средой, практически не имеют языковых контактов, и при таком подходе не реализуется развитие навыков устной речи.

Существует ещё один факт, который следует упомянут в заключении. Предмет DaZ принято считать временным явлением для школ Германии, поскольку приток мигрантов (беженцев) в будущем планируется быть незначительным, и не будет необходимости в дальнейшем включать это предмет в учебный план школ. Соответственно этому предмету не уделяется достаточно внимания на всех уровнях школьного образования, а также в ведомственных учреждениях.

Таким образом, на примерах работы двух школ Германии была впервые подробно рассмотрена и проанализирована система обучения немецкому как второму иностранному языку в настоящее время и сделаны основные выводы относительно её качества. Приведенные в статье данные могут быть использованы преподавателями немецкого языка в России для совершенствования своих учебных курсов по немецкому языку как в школе, так и рамках дополнительного языкового образования

Авторы выражают благодарность директору государственной гимназии № 10 (г. Эрфурт, Тюрингия) г-ну Андреасу Лёйбе и директору общеобразовательной школь № 3 «Kolpingschule» (2. Эрфурт, Тюрингия) за предоставленную возможность провести педагогическое наблюдение на базе подведомственных учреждений.

\section{Список источников}

1. Deutsch als Zweitsprache: Lehrplan für allgemeinbildenden Schulen. Sekundarstufe I. 2020 (Erprobungsfassung) URL: http://www.schulportal-thueringen.de/media/detail (accessed: 29.03.2021).

2. Heilmann B. 2013. Diagnostik \& Förderung - leichtgemacht: Deutsch als Zweitsprache. Hrsg. W. Grießhaber. Stuttgart, Ernst Klett Sprachen GmbH, 133 p.

3. Thüringer Ministerium für Bildung, Jugend und Sport (Hrsg.) 2018. Einfach und schnell erklärt: Das Schulsystem in Thüringen. Erfurt, 17 p.

\section{Peferences}

1. Apeltauer E. 1997. Grundlagen des Erst- und Fremdsprachenerwerbs. Eine Einführung [Apeltauer E. 1997. Grundlagen des Erst- und Fremdsprachenerwerbs. Eine Einführung]. Berlin, München u.a., Publ. Langenscheid, 176 s. (in German) 
2. Boeckmann K.B. 1997. Zweisprachigkeit und Schulerfolg: das Beispiel Burgenland [Bilingualism and school success: the example of Burgenland]. Frankfurt am Main, Berlin u.a.: Publ. Lang, 208 s. (in German)

3. Boeckmann K.B. 2016. Plurilinguale Bildung: Habitus im Mehrsprachenunterricht. In: [M.Langror \& V.Jovanovic (Hrsg.), Facetten der Mehrsprachigkeit - Reflets du plurilinguismo. Die Wahl der Sprachen: Luxemburg in Europa - Le choix des langues: le Luxembourg à lheure europélnne]. Bern: Peter Lang, s. 53-63 (in German)

4. Jung B., Günther H. 2016. Erstsprache, Zweitsprache, Fremdsprache: Eine Einführung. 3.Auflage. Weinheim und Basel: Beltz Verlag, 256 s. (in German)

5. Kielhöfer B., Jonekeit S. 2006. Zweitsprachige Kindererziehung [Raising children in two languages]. Tübingen, Staufenburg, 109 s. (in German)

6. Köppe R. 1997. Sprachentrennung im frühen bilingualen Erstspracherwerb Französisch, Deutsch [Separation of languages in early bilingual first language acquisition French and German]. Tübingen, Publ. Narr, 309 s. (in German)

7. Roche J. 2020. Fremdsprachenerwerb, Fremdsprachendidaktik. 4., überarbeitete und erweiterte Auflage. Tübingen: Narr Francke Attempto Verlag GmbH, 420 s. (in German)

8. Štefánik J. 2005. International Bilingualism Revisited [International Bilingualism Revisited]. In: [Files from the Vienna Colloquium on Individual and Social Multilingualism], October 5-6. Wien, Publ. Praesens: 28-46 (in German)

9. Weinreich U. 1977. Sprache in Kontakt. Ergebnisse und Probleme der Zweisprachigkeitsforschung [Language in contact. Results and problems of bilingualism research]. München, Beck, 281 s. (in German)

\section{ИНФОРМАЦИЯ ОБ АВТОРАХ}

Безрукова Елена Ивановна, кандидат филологических наук, доцент, доцент кафедры немецкого и французского языков педагогического института Белгородского государственного национального исследовательского университета, Белгород, Россия

Колесников Алексей Анатольевич, кандидат филологических наук, доцент кафедры немецкого и французского, декан факультета иностранных языков педагогического института Белгородского государственного национального исследовательского университета, Белгород, Россия

\section{INFORMATION ABOUT THE AUTHORS}

Elena I. Bezrukova, Candidate of Philology, Associate Professor, Associate Professor of the German and French Languages Department of the Pedagogical Institute, Belgorod State National Research University, Belgorod, Russia

Aleksey A. Kolesnikov, Candidate of Philology, Associate Professor of the German and French Languages Department, Dean of the Foreign Languages Faculty of the Pedagogical Institute, Belgorod State National Research University, Belgorod, Russia 